\title{
Thermal Stability of Lithiated Silicon Anodes with Electrolyte
}

\author{
Yoon-Soo Park and Sung-Man Lee* \\ Department of Advanced Materials Science and Engineering, Kangwon National University, Chuncheon, \\ Kangwon-Do 200-701, Korea. ${ }^{*}$ E-mail: smlee@kangwon.ac.kr \\ Received September 14, 2010, Accepted November 4, 2010
}

\begin{abstract}
The thermal behavior of lithiated Si anodes has been investigated using differential scanning calorimetry (DSC). In particular, the effect of Si particle size on the thermal stability of a fully lithiated Si electrode was investigated. For DSC measurements, a lithiated Si anode was heated in a hermetically sealed high-pressure pan with a polyvinylidene fluoride (PVDF) binder and a $1 \mathrm{M} \mathrm{LiPF}_{6}$ solution in an ethylene carbonate (EC)-diethyl carbonate (DEC) mixture. The thermal evolution around $140{ }^{\circ} \mathrm{C}$ increases with lithiation and with decreasing particle size; this phenomenon is attributed to the thermal decomposition of the solid electrolyte interface (SEI) film. Exothermic peaks, following a broad peak at around $140{ }^{\circ} \mathrm{C}$, shift to a lower temperature with a decrease in particle size, indicating that the thermal stability of the lithiated $\mathrm{Si}$ electrode strongly depends on the Si particle size.
\end{abstract}

Key Words: Li-ion battery, Si anode, Thermal stability, DSC

\section{Introduction}

Graphitic carbon is currently used as the anode in lithium (Li)-ion batteries. However, because of the increasing demand for Li-ion batteries with high specific energy density, various materials are being investigated with the aim of finding an alternative to graphite (theoretical capacity: $372 \mathrm{mAhg}^{-1}$ ) for use as an anode material. In this respect, silicon-based anode materials have attracted considerable attention because silicon (Si) has a theoretical capacity of $4200 \mathrm{mAhg}^{-1}$. Replacing graphitic carbon with Si as the anode material can lead to an increase in the specific anode capacity by a factor of 10 and can significantly increase the energy density of the battery. However, unfortunately, the use of Si results in a large volume change during Li alloying/dealloying, leading to poor cyclic performance. Several studies on $\mathrm{Si}$ anode materials have circumvented this problem by using nanostructured $\mathrm{Si}$ such as $\mathrm{Si}$ thin films, ${ }^{1,2}$ nanosized $\mathrm{Si},{ }^{3,4}$ and $\mathrm{Si}$ nanotubes, ${ }^{5}$ which has resulted in considerable improvements in cyclability.

The safety of Li-ion batteries is a major concern for their potential application. In particular, it is essential to understand the exothermic reactions between the electrode materials and electrolyte at elevated temperatures to enhance the thermal safety of Li-ion batteries. Hence, it is important to investigate the thermal behavior of Si-based anode materials before they can be considered for commercial application. However, only a few studies have been conducted in this regard thus far. Recently, the thermal reactions of lithiated Si with electrolytes were studied using accelerating rate calorimetry (ARC) over the temperature range of $100-350{ }^{\circ} \mathrm{C} .{ }^{6}$ It should be noted that Si powder with quite a large particle size ( -325 mesh) was used for the fabrication of lithiated Si electrodes. It is generally known that the use of fine Si particles is preferred for enhancing the cycling stability of Si-based anodes.

In this study, the thermal stability of lithiated Si electrodes was investigated using differential scanning calorimetry (DSC). In particular, the effect of particle size on the thermal stability of a fully lithiated $\mathrm{Si}$ electrode was investigated.

\section{Experimental}

Si powders with different particle sizes - S1 (15 $\mu \mathrm{m}, 99 \%$, Aldrich), S2 (5 $\mu \mathrm{m}, 99.9 \%$, High Purity Chemicals), S3 (30 - 50 nm, 98\%, Nanostructured \& Amorphous Materials, Inc.) - were used. Scanning electron microscopy (SEM) images of these $\mathrm{Si}$ particles are shown in Fig. 1. The Si electrodes were formed in the following manner: A slurry composed of $90 \mathrm{wt} \%$ active
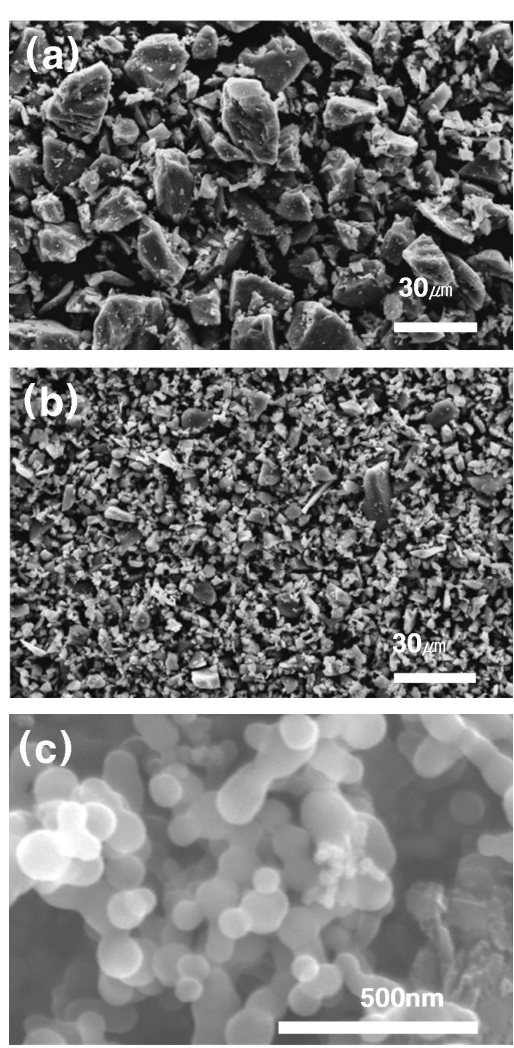

Figure 1. Field emission scanning electron microscopy (FE-SEM) images of Si powder used in this study: (a) S1, (b) S2, (c) S3. 
materials (Si) and a $10 \mathrm{wt} \%$ polyvinylidene fluoride (PVDF) binder was mixed in $\mathrm{N}$-methyl pyrrolidinone. This mixture was spread onto a copper foil and then dried at $120^{\circ} \mathrm{C}$ for $12 \mathrm{~h}$. The thermal properties of the lithiated $\mathrm{Si}$ anodes were evaluated by precharging them in a 2016 coin-type half cell with a $1 \mathrm{M} \mathrm{LiPF}_{6}$ solution in an ethylene carbonate-diethyl carbonate (EC-DEC) (1:1 by volume, PANAX ETEC Co., Ltd., Korea) electrolyte; the charging was interrupted when the cells were lithiated to a prescribed charge. The charged cells were disassembled in a glove box. Discs with the copper foil were punched from the electrode sheets without removal of the electrolyte; these discs were then transferred into a high-pressure chrome-nickel steel pan with a gold-plated copper seal. We did not control the amount of electrolyte, but there was enough amount of electrolyte in a sealed DSC pan. DSC analysis (NETZSCH, Germany) was performed at a heating rate of $10{ }^{\circ} \mathrm{C} \cdot \mathrm{min}^{-1}$ over a temperature range of $50-500{ }^{\circ} \mathrm{C}$. In order to measure the heat generation $(\mathrm{J} / \mathrm{g})$, the weight of Si and PVDF without electrolyte was used. The weight of each DSC pan with sample was measured before and after the experiment. The weight was constant in all cases, indicating that there were no leaks during the experiments.

\section{Results and Discussion}

Fig. 2(a) shows the first charge (lithiation) curves of a series of S2 cells that were stopped at five different states of charges

(a)

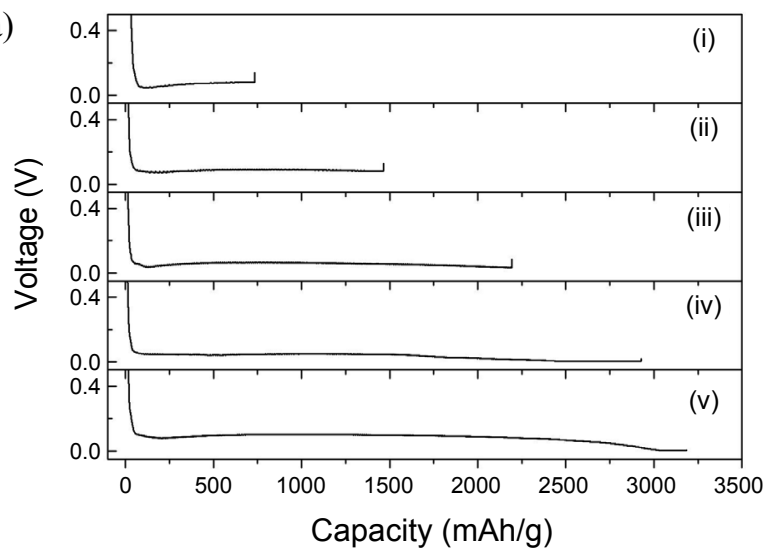

(b)

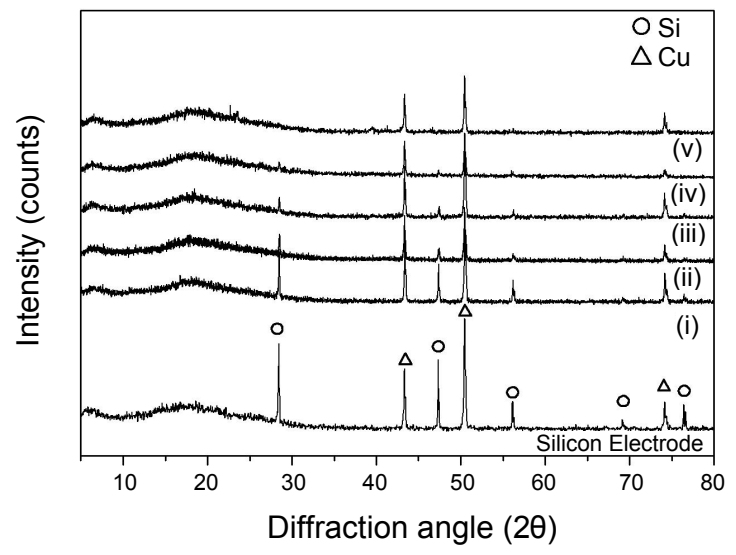

Figure 2. (a) First charge (lithiation) curves of a series of $\mathrm{S} 2$ cells that were stopped at five different states of charges (SOCs) and (b) XRD patterns of electrodes have a five different states of charges (SOCs).
(SOCs) for DSC analysis; these SOCs corresponded to the capacities of 732, 1464, 2195, 2928, and $3200 \mathrm{mAhg}^{-1}$ that are equivalent to $\mathrm{Li}_{0.77} \mathrm{Si}, \mathrm{Li}_{1.54} \mathrm{Si}, \mathrm{Li}_{2.31} \mathrm{Si}, \mathrm{Li}_{3.08} \mathrm{Si}_{1} \mathrm{Li}_{3.35} \mathrm{Si}$, respectively. The cell was charged at a constant current of $0.2 \mathrm{~mA} \cdot \mathrm{cm}^{-2}$. As shown in Fig. 2(b), the ex situ XRD patterns of Si electrodes at each corresponding state indicated that the intensity of the Si peaks decreases with increasing lithiation capacity, and the amorphous $\mathrm{Li}_{\mathrm{x}} \mathrm{Si}$ phase coexists with the crystalline Si phase. When the charge capacity reaches up to $3200 \mathrm{mAhg}^{-1}$, the Si peak nearly disappears.

Fig. 3 shows DSC profiles of the S2 electrodes with electrolyte charged with various SOC shown in Fig. 2; these DSC profiles were determined by subtracting the baseline obtained by reheating the sample after the first thermal analysis from the initial profile. Typically, the heat evolution peak is detected in three temperature regions - $\mathrm{A}\left(100-200{ }^{\circ} \mathrm{C}\right), \mathrm{B}\left(250-350{ }^{\circ} \mathrm{C}\right)$, and $\mathrm{C}\left(350-500{ }^{\circ} \mathrm{C}\right)$. These exothermic peaks increase with the capacity, indicating that the total heat generation increases with lithiation. The sharp peak $\mathrm{C}$ increases remarkably and then shifts to a lower temperature. The $\mathrm{Li}_{15} \mathrm{Si}_{4}$ phase seems to be substantially responsible for the highly exothermal reaction of

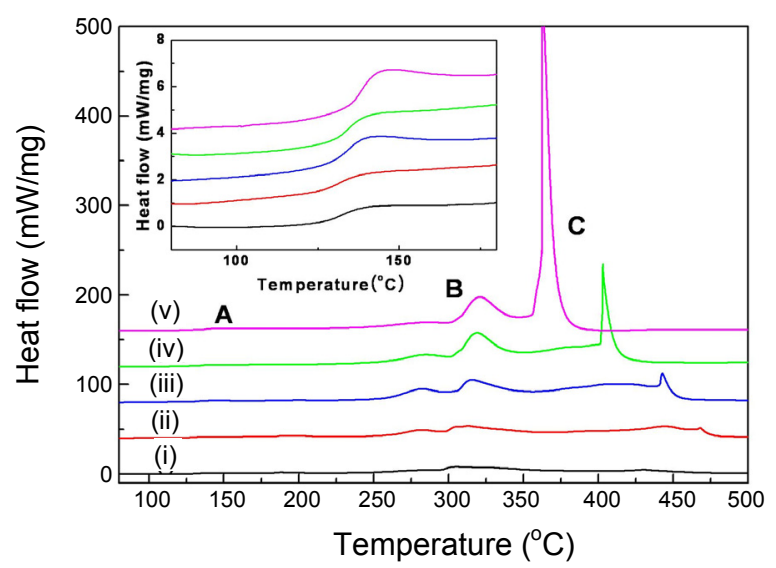

Figure 3. Differential scanning calorimetry (DSC) curves of S2 electrodes with different SOCs at a scan rate of $10{ }^{\circ} \mathrm{C} \cdot \mathrm{min}^{-1}$.

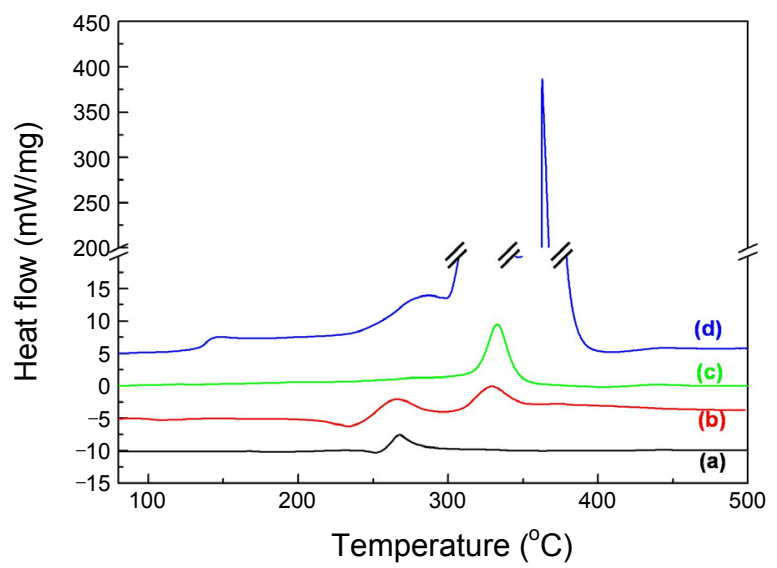

Figure 4. DSC curves of (a) EC:DEC/1 M LiPF 6 electrolyte, (b) PVDF with electrolyte, (c) S2 electrode without electrolyte and (d) S2 electrode with electrolyte. 


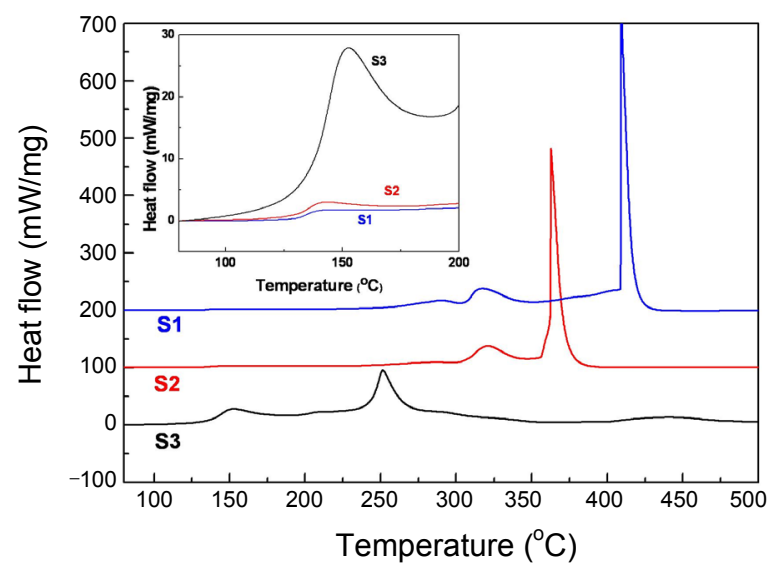

Figure 5. DSC curves of fully lithiated Si electrodes with different particle sizes.

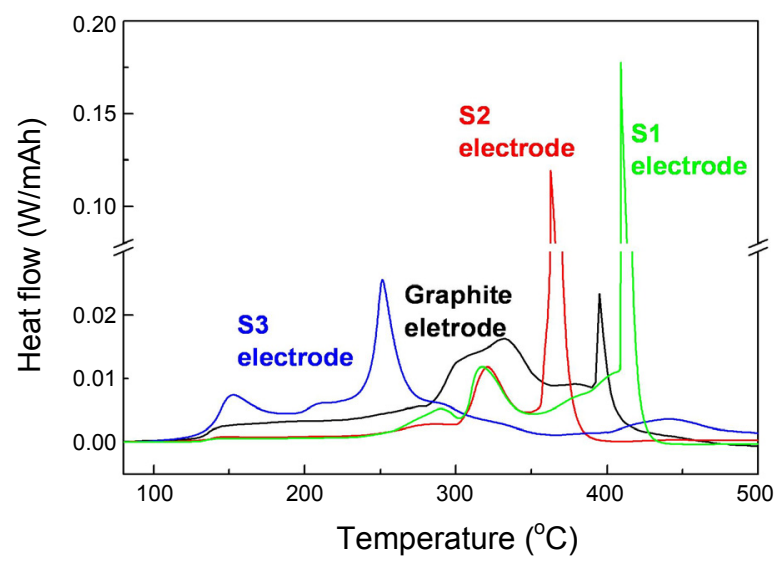

Figure 6. Heat flow curves normalized for the lithium storage capacity for lithiated graphite, S1, S2, and S3 electrodes.

a fully charged electrode. Interestingly, the thermal evolution at approximately $140{ }^{\circ} \mathrm{C}$ (region A) increases with lithiation, as shown in the inset of Fig. 3.

Fig. 4 shows the DSC curves of electrode components that we used; (a) EC-DEC/1 M LiPF6 electrolyte, (b) PVDF binder with electrolyte, (c) S2 electrode without electrolyte, and (d) S2 electrode with electrolyte. Electrolyte and PVDF also had their thermal reactions as shown in sample (a) and (b), but the thermal evolution was very small to compare with sample (d). And sample (c) also shows an exothermal peak at $333^{\circ} \mathrm{C}$. But the thermal evolution was also very small to compare with sample (d). In Fig. 3, total heat generation increased with lithiation. Thus, the thermal evolution of S2 electrode is seems to be mainly due to the reaction between lithiated silicon and electrolyte.

Fig. 5 shows the DSC profiles for fully charged electrodes with three different Si particle sizes. S1, S2 and S3 electrodes were charged to $0.005 \mathrm{~V}$ and the capacities were $3700 \mathrm{mAh} / \mathrm{g}$, $3200 \mathrm{mAh} / \mathrm{g}$ and $3200 \mathrm{mAh} / \mathrm{g}$, respectively. As shown in the inset of Fig. 5, the thermal evolution at approximately $140{ }^{\circ} \mathrm{C}$ is related to the particle size, the thermal evolution at approximately $140{ }^{\circ} \mathrm{C}$ increases with decreasing particle size for fully lithiated Si electrodes. Since the thickness of a solid electrolyte
Table 1. Heat evolution for S1, S2, S3, and carbon-coated natural graphite electrodes heated up to 300 and $500{ }^{\circ} \mathrm{C}$

\begin{tabular}{|c|c|c|c|}
\hline & \multicolumn{3}{|c|}{ Heat generation $(\mathrm{J} / \mathrm{mAh})$} \\
\hline & $\mathrm{RT}-300{ }^{\circ} \mathrm{C}$ & $\mathrm{RT}-350{ }^{\circ} \mathrm{C}$ & $\mathrm{RT}-500{ }^{\circ} \mathrm{C}$ \\
\hline $\begin{array}{l}\text { S1 electrode } \\
(3,700 \mathrm{mAh} / \mathrm{g})\end{array}$ & 2 & 4.7 & 12.4 \\
\hline $\begin{array}{l}\text { S2 electrode } \\
(3,200 \mathrm{mAh} / \mathrm{g})\end{array}$ & 1.6 & 3.4 & 8.1 \\
\hline $\begin{array}{l}\text { S3 electrode } \\
(3,200 \mathrm{mAh} / \mathrm{g})\end{array}$ & 6 & 6.3 & 6.36 \\
\hline $\begin{array}{l}\text { Graphite electrode } \\
\quad(349 \mathrm{mAh} / \mathrm{g})\end{array}$ & 4.9 & 7.8 & 12.8 \\
\hline
\end{tabular}

interface (SEI) layer on an Si film anode increases with lithiation ${ }^{7}$ and more SEI film is formed in the electrode with a smaller particle size, it is suggested that the thermal evolution at approximately $140{ }^{\circ} \mathrm{C}$ is mainly due to the thermal decomposition of the SEI film. The major exothermic peak is significantly reduced and shifted to the lower temperature side as the Si particle size decreases. This may be because the reduced diffusion path and larger surface area in smaller Si particles facilitate the evolution of lithium at lower temperatures, resulting in an exothermic reaction with electrolyte. The total thermal evolution of S1, S2, and S3 electrodes when heated up to $500{ }^{\circ} \mathrm{C}$ was observed to be 39800,26000 , and $23800 \mathrm{Jg}^{-1}$, respectively. Thermal evolution decreases with the particle size of Si. However, when $\mathrm{S} 1, \mathrm{~S} 2$, and $\mathrm{S} 3$ were heated up to $300{ }^{\circ} \mathrm{C}$, their total thermal evolution was observed to be 6300,4500 , and $22200 \mathrm{Jg}^{-1}$, respectively. In the case of the $\mathrm{S} 3$ electrode, most exothermic reactions occur below $300{ }^{\circ} \mathrm{C}$; however, in the cases of $\mathrm{S} 1$ and $\mathrm{S} 2$ electrodes, the major exothermic peak is detected at $412{ }^{\circ} \mathrm{C}$ and $362{ }^{\circ} \mathrm{C}$, respectively.

As a result, as the particle size of silicon decreases, more lithium becomes available for the reaction with electrolyte at lower temperatures, and thus a thermal evolution at lower temperatures increases.

Fig. 6 shows the heat flow curves, as normalized for the $\mathrm{Li}$ storage capacity, for Si and carbon-coated natural graphite electrodes. The corresponding thermal evolution, as calculated from the heat flow curves in Fig. 6, is provided in Table 1.The thermal evolution below $300{ }^{\circ} \mathrm{C}$ for S1and S2 electrodes is less than that of graphite electrode. This is consistent with a recent result by Wang and Dahn using ARC, ${ }^{6}$ in which for similarly lithiated samples, the self-heating rate of $\mathrm{Si}$ (with a particle size of -325 mesh; same as the S1 particle size in this study) electrode reacting with the electrolyte was less than that of the graphite electrode up to $350{ }^{\circ} \mathrm{C}$. In the case of S3 electrode, most thermal evolution proceeds below $300{ }^{\circ} \mathrm{C}$ while the total thermal evolution up to $500{ }^{\circ} \mathrm{C}$ is lower than that for the $\mathrm{S} 1, \mathrm{~S} 2$ and graphite electrodes. It is known that thermal evolution at low temperatures below $300{ }^{\circ} \mathrm{C}$ is critical to thermal runaway of Li-ion batteries. Thus, for practical application of nano-sized $\mathrm{Si}$ that is promising as a high capacity anode material for Li-ion cells, the thermal evolution at such low temperatures should be suppressed. 


\section{Conclusions}

The effect of the Si particle size on the thermal behavior of fully lithiated Si anodes was investigated using DSC. Typically, heat evolution peak is detected in three temperature regions around $140{ }^{\circ} \mathrm{C}$, around $320^{\circ} \mathrm{C}$, and above $350{ }^{\circ} \mathrm{C}$ - for electrodes with large Si particle size above $5 \mu \mathrm{m}$. These exothermic peaks increase with the lithiated lithium content, and correspondingly the total heat generation increases. With increasing the level of lithiation, the major exothermic peak has significantly increased and also shifted to a lower temperature.

The thermal stability of the Si anode depends on the Si particle size. As the particle size decreases, the heat evolved around $140{ }^{\circ} \mathrm{C}$, attributed to the thermal decomposition of SEI film, increases, and the latter two thermal evolution peaks are significantly reduced and shifted to a lower temperature. In the case of the nanosized Si electrode, a significant heat evolution occurs around $250{ }^{\circ} \mathrm{C}$.
Acknowledgments. This research was financially supported by the Ministry of Knowledge Economy (MKE) and Korea Institute for Advancement of Technology (KIAT) through the Research and Development for Regional Industry (Project no. 70005106).

\section{References}

1. Takamura, T.; Ohara, S.; Uehera, M.; Suzuki, J.; Sekine, K. J. Power Sources 2004, 129, 96.

2. Yin, J.; Wada, M.; Yamamoto, K.; Kitano, Y.; Tanase, S.; Sakai, T. J. Electrochem. Soc. 2006, 153, A472.

3. Gomez-Camer, J. L.; Morales, J.; Sanchez, L. Electrochem. SolidState Lett. 2008, 11, A101.

4. Graetz, J.; Ahn, C. C.; Yazami, R.; Fultz, B. Electrochem. SolidState Lett. 2003, 6, A194.

5. Park, M. H.; Kim, M. G.; Joo, J.; Kim, K.; Kim, J.; Ahn, S.; Cui, Y.; Cho, J. Nano Lett. 2009, 9, 3844.

6. Wang, Y.; Dahn, J. R. Electrochem. Solid-State Lett. 2006, 9, A340.

7. Lee, Y. M.; Lee, J. Y.; Shim, H. T.; Lee, J. K.; Park, J. K. J. Electrochem. Soc. 2007, 154, A515. 